\title{
Furnace Charging Comprehensive Optimization Technology of the Bell-type Annealing Process
}

\author{
Zhen-hua BAI, ${ }^{1,2) *}$ Ya-ya CUI, ${ }^{1)}$ Jun ZHANG, ${ }^{1)}$ Qi-lin $\mathrm{LI}^{11}{ }^{1)}$ Bo-yang $\mathrm{LI}^{11}$ and Yu XING ${ }^{1)}$ \\ 1) National Engineering Research Center for Equipment and Technology of Cold Strip Rolling, Yanshan University, Qinhuangdao, \\ Hebei, 066004 China. $\quad$ 2) State Key Laboratory of Metastable Materials Science and Technology, Yanshan University, \\ Qinhuangdao, Hebei, 066004 China.
}

(Received on August 23, 2016; accepted on March 16, 2017; J-STAGE Advance published date: May $19,2017)$

\begin{abstract}
Sticking defect in the bell-type annealing process is closely related to furnace charging technology. Unsuitable furnace charging technology increases the additional radial pressure of some coils in the furnace and leads to sticking defect. A suitable furnace charging comprehensive optimization technology of the bell-type annealing process is introduced, which aims at sticking prevention. This technology was developed after field experiments and theoretical analyses based on defining the concept of sticking index, considering the influences of coiling technology, coil size, product specifications, and annealing technology on the steel internal stress. The coil work-base quantity was as close as possible to the theoretical minimum value, and the average and peak sticking index value of the same batch of coils as the target were minimized, balanced with production efficiency and defect prevention. This technology was applied to the production practice of a cold-rolled sheet plant, achieving good using effect with furnace charging efficiency. Production increased, and sticking defect decreased. Considerable economic benefit for the enterprise was created with further popularization and application values.
\end{abstract}

KEY WORDS: bell-type annealing; sticking; furnace charging; optimization.

\section{Introduction}

In recent years, the demand for strip product has been increasing with the rapid development of household appliances, automobiles, electronics, military equipment, construction tools, shipbuilding materials, and aerospace equipment, among others. Correspondingly, the market competition of strip products has become increasingly fierce with the high rigorous quality requirements of users. As an important intermediate process between cold and temper rolling in the strip production process, annealing plays an indispensable role in controlling the strip mechanical properties. Based on the strip heat treatment, annealing is classified into two categories: bell-type and continuous. Bell-type annealing involves stacking tightly wound coils and heating them in a protective gas environment. ${ }^{1)}$ Bell-type annealing is widely used in the cold-rolled strip annealing production because of its strip width and thickness unlimited. This annealing technology is widely adjustable, and its production planning is flexible. ${ }^{2)}$

Sticking defect has been a serious quality problem in the bell-type annealing process. The occurrence of sticking defect is closely related to the product properties (such as the strip specification, steel grade, shape quality, and section profile) and the upstream coiling technology. Sticking defect

\footnotetext{
* Corresponding author: E-mail: bai_zhenhua@aliyun.com DOI: http://dx.doi.org/10.2355/isijinternational.ISIJINT-2016-476
}

is also closely related to the annealing technology (such as anneal temperature, soaking time, heating and cooling rate), the furnace structure, and the charging method of the belltype annealing process.

Concerning the sticking defect in the bell-type annealing process, O. Pawelski ${ }^{3)}$ analyzed the quantitative effect on sticking effect of annealing parameters by a test, which showed the influence of annealing temperature, loading of specimens, soaking time, surface roughness, and intermediate layers on the welding intensity. X.-c Zhang ${ }^{4}$ claimed that the reciprocal transformation of $\mathrm{Fe}$ and iron oxide during annealing is the main reason of sticking defect, and prevention measure was given by optimizing the annealing technology, cold rolling technology and temper rolling technology. S. S. Sahay ${ }^{5)}$ developed an integrated model to predicting spatial and temporal evolution of temperature, microstructure and mechanical properties based on fundamental principles of heat transfer, microstructural evolution kinetics and microstructure-property correlation. B. Jiang ${ }^{6}$ ) established mathematic models of heat conduction and thermal stress, obtained the coupled temperature and stress distribution in the coil, which was helpful to optimize the coil annealing process. S. J. Park ${ }^{7)}$ proposed a new unit layer model for the equivalent thermal conductivity of layered steel strips, which is a function of strip thickness, surface characteristics and compressive stress. K. Tanaka ${ }^{8)}$ studied the heat transmission and calculated the theoretical temperature distribution in the bell-type annealing furnace. 
H. Nakashima ${ }^{9)}$ investigated the influence of annealing conditions on surface characteristics by changing annealing soaking temperature and atmospheric gas composition. J. T. Park ${ }^{10)}$ reported that the heating rate, annealing temperature and time, and cooling rate are the main factors influence the formation of annealing texture.

Their studies on thermal stress, thermal conductivity and chemical surface conditions in the coils do have effects to reduce the sticking defect. However, the bottom coil were much likely to occurred sticking defects than the top one with the same annealing technology in the same furnace. Furthermore, the product properties and the upstream coiling process cannot be controlled in the annealing process, the annealing technology cannot be freely adjusted because it is restricted by the final product property requirements, and the furnace structure has been basically fixed after commissioning and cannot be changed significantly during the production process. Therefore, optimizing the combination mode of coils and the charging order in the furnace has become one of the key measures to reduce the sticking occurrence rate in the bell-type annealing process.

Concerning this charging problem in the bell-type annealing process, Y. Liu ${ }^{11)}$ proposed a mathematical model to minimize the number of coil stacks and the total heating treatment time, and constructed a two-stage intelligent optimization algorithm based on adaptive genetic and ant colony algorithms. J. $\mathrm{Li}^{12)}$ alleviated the handwork intensity through the automatic calculation of furnace charging in computer. X.-p Zhang ${ }^{13)}$ suggested a multi-knapsack model with multi-furnace type and uncertain furnace numbers and proposed a new single parent genetic algorithm based on local gene-segment reservation selecting operator and inversion-crossover inheriting operator for solving the model. X.-d. Wang ${ }^{14)}$ developed an expert system for automatic combination of stacks of coils in a batch annealing shop by using expert system tools CLIPS and combine the expert system with a genetic algorithm for increasing optimizing capacity. Q.-1. Liu ${ }^{15)}$ proposed an optimal scheduling method for a bell-type batch annealing by combining an improved genetic algorithm with discrete event simulation technique. However, their studies focused on production efficiency improvement and scarcely considered defect prevention.

Therefore, the overall effect is not good. Quality defects, such as sticking caused by unsuitable charging, are still problems in field production. Ensuring production efficiency and reducing the defect occurrence rate to a minimum in the furnace charging process require further study. The present study is conducted based on this background.

\section{Internal Strip Force Analysis of the Coils in the Bell- type Annealing Process}

Conventional bell-type annealing furnace annealing is performed with single stack and tight coils. The coils are charging together and separated by convection plates in the furnace (as shown in Fig. 1). Considering the radial stress of the strip is equal in circumference and ignoring the influence of its own gravity on the coil internal stress distribution are important in analyzing the stress condition of the coil in the bell-type annealing process (as shown in Fig. 2). During

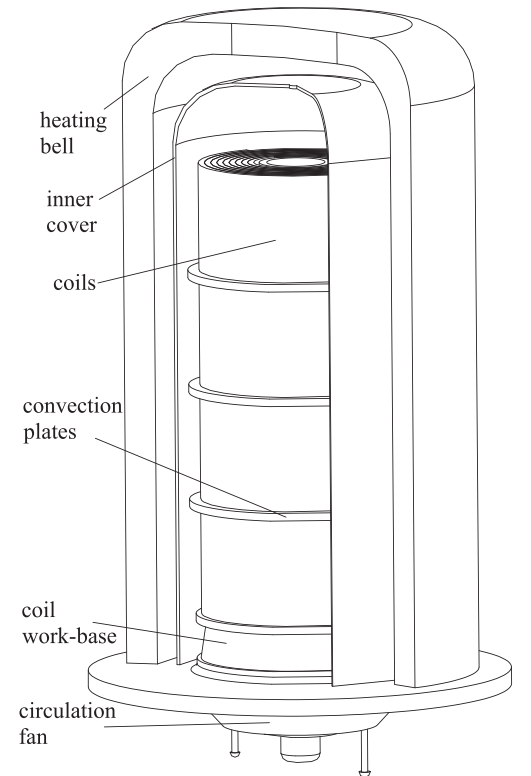

Fig. 1. Diagram of coils in the bell-type annealing process.

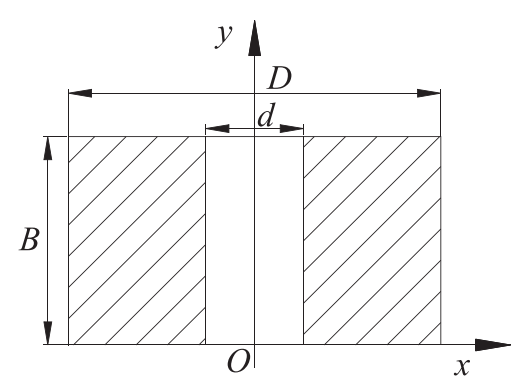

Fig. 2. Internal coordinate system of the coil.

the annealing process, the stress condition of the top coil is relatively simple without bearing any external force, but only its own gravity. The strip radial stress in the coil can be approximately expressed by Formula (1).

$$
\sigma_{r x y}=\sigma_{r_{0} x y}+\sigma_{r_{z} x y}
$$

where $\sigma_{r x y}$ is the interlayer radial pressure in the strip of coordinates $(x, y) ; \sigma_{r_{0} x y}$ is the initial radial pressure related to the coiling process of the upstream step, product specifications and steel grade in the strip of coordinates $(x, y) ;{ }^{16)}$ $\sigma_{r_{z} x y}$ is the additional radial pressure caused by thermal stress of the bell-type annealing process in the strip of coordinates $(x, y) .{ }^{17)}$

However, the lower part of the coils will also bear the additional axial pressure generated by the weight of the upper coils and the convection plates in addition to its own gravity. Minimal coil axial compressive deformation occurs because of the additional axial pressure. At the same time, additional deformation of the coils occurs in the radial direction because of the Poisson effect, this condition leads to additional pressure in the radial direction (as shown in Fig. 3). Thus, the radial pressure in the lower layer strip can be expressed by Formula (2).

$$
\sigma_{r x y}=\sigma_{r_{0} x y}+\sigma_{r_{z} x y}+\sigma_{r_{f} x y}
$$

where $\sigma_{r_{f} x y}$ is the additional radial pressure of the No. $\mathrm{i}$ layer strip caused by the weight of the upper coils and convection plates. This pressure depends on the quantity and 


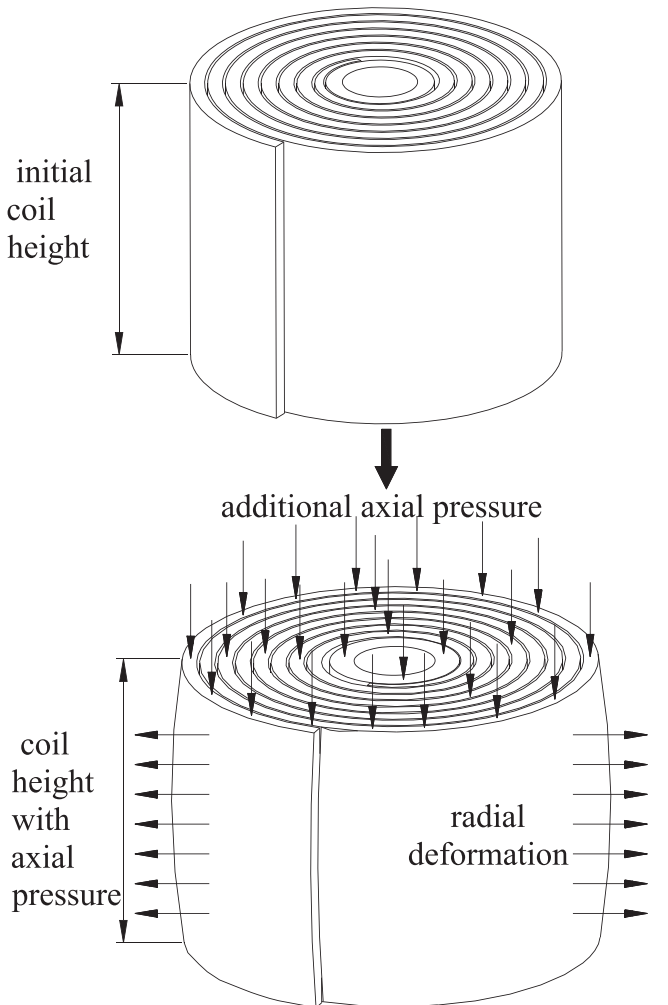

Fig. 3. Diagram of stress and additional deformation of lower layer coils in the bell-type annealing process.

weight of the upper coils.

Sticking is a phenomenon of the strip local welding together under radial pressure in the bell-type annealing process. ${ }^{18)}$ At a certain temperature, a greater radial pressure results in easier welding of the strip and increases sticking probability. Correspondingly, given that the top coil in the bell-type annealing furnace has no additional radial stress, the strip radial stress of the coil is merely the superimposed of the initial radial and thermal stresses. Thus, sticking defect scarcely occurs. However, the coil at the bottom of the furnace bears the largest additional axial pressure applied by the weight of the upper coils and the convection plates. Therefore, the additional and the corresponding radial pressures are the largest, the occurrence probability of sticking defect is higher. The furnace charging process in the bell-type annealing process involves placing a batch of coils annealed into the furnace by permutation and combination. If the furnace charging process is unsuitable, then the additional radial pressure in part of the coils in the bell-type annealing furnace will become too large and lead to a higher occurrence rate of sticking in the batch of coils. This phenomenon is the influence mechanism of the furnace charging process on sticking defect. Correspondingly, the optimization of the furnace charging process involves optimizing the combination of a batch of coils to be annealed to control the radial stress of all the coils in a certain range without the local high stress phenomenon to decrease the occurrence rate of sticking defect.

\section{Furnace Charging Comprehensive Optimization Technology of the Bell-type Annealing Process}

\subsection{Introduction of the Concept of Sticking Index}

In addition to the sticking defect occurrence rate in the bell-type annealing process of the coils, the concept of sticking intensity exists. Sticking intensity is the difficulty degree of the separation of sticking between the interlayer strips. A larger sticking intensity corresponds to an increased difficulty in separating the strip and a greater influence on the finished surface quality and the normal production of downstream processes. In addition to the radial pressure, sticking intensity is also closely related to the annealing process (such as annealing temperature and soaking time) and steel grade. Thus, the new concept of sticking index is introduced to quantitatively describe the occurrence probability of sticking defect and sticking intensity in the bell-type annealing process and to lay the foundation for the optimization of the furnace charging process. This concept is expressed by $\xi$ as shown in Formula (3).

$$
\xi=\frac{\sigma_{r \max }-\sigma_{r}^{*}}{\sigma_{r}^{*}}
$$

where $\sigma_{r \max }$ is the maximum radial compressive stress in the strip, $\sigma_{r \max }=\max \left\{\sigma_{r x y}\right\} ; \sigma_{r}^{*}$ is the critical radial stress of a specific steel-grade strip when sticking defect occurs under certain annealing temperature and soaking time, which can be obtained through laboratory tests.

The formula indicates that the sticking defect occurs in the coil if the sticking index $\xi \geq 0$. A larger sticking index $\xi$ is corresponds to an increased probability of the occurrence of sticking defect and higher sticking intensity. Meanwhile, sticking index $\xi$ is calculated with $\sigma_{r \max }$ and $\sigma_{r}^{*}$ under specific annealing technology (annealing temperature and soaking time). Therefore, the temperature deviation in batch annealing system does not need to be listed separately since it has been considered in $\sigma_{r \max }$ and $\sigma_{r}^{*}$.

\subsection{Establishment of the Furnace Charging Compre- hensive Optimization Model}

Before setting up the furnace charging comprehensive optimization model, the characteristic parameters of the coils for furnace charging optimization and the coil workbase should be defined. These parameters mainly include the following: (1) the quantity of coils for furnace charging optimization $N$; (2) the quantity of available coil workbases for bell-type annealing $M$; (3) the serial number of coil work-bases $m, m=1,2, \cdots, M$; (4) the quantity of coils in each coil work-base after furnace charging $k_{m}, \sum_{m=1}^{M} k_{m}=N$; (5) the serial number in the furnace from top to bottom $i$; (6) the serial number of all coils after furnace charging $n_{m i}$, with the following order of coils: $n_{11}, n_{12}, \cdots, n_{1 i}, \cdots, n_{1 k_{1}}, \cdots, n_{m 1} \cdots, n_{m k_{m}}, \cdots, n_{M 1} \cdots, n_{M k_{M}}$; (7) the maximum allowed furnace charging height of the bell-type annealing furnace $H_{L u}$; (8) the convection plate weight $G_{d}$. Thus, after furnace charging, the weight of the upper coils and convection plates, which any of the No. i coil in the No. $\mathrm{m}$ coil work-base bears, can be expressed by Formula (4). 


$$
T_{m i}=\left\{\begin{array}{lc}
\sum_{j=1}^{i-1} G_{m j}+(i-1) G_{d} & i>1 \\
0 & i=1
\end{array} \ldots \ldots \ldots \ldots \ldots . . . . . .(4)\right.
$$

where $G_{m j}$ is the weight of the No. $\mathrm{j}$ coil in the No. m coil work-base, $G_{m j}=\pi \rho B_{m j}\left(R_{m j}^{2}-r_{m j}^{2}\right), \rho$ is the density of strip, $B_{m j}$ is the width of the No. $\mathrm{j}$ coil in the No. m coil work-base, $R_{m j}$ is the outer diameter of the No. $\mathrm{j}$ coil in the No. m coil work-base, and $r_{m j}$ is the inner diameter of the No. $\mathrm{j}$ coil in the No. m coil work-base.

The coiling process before furnace charging and the annealing process after furnace charging are determined for a single coil used for the optimization of a specific batch. Correspondingly, the radial stress caused by coiling tension and thermal stress are also determined. Based on Formulas (1) and (2), the interlayer maximum radial pressure of the No. $i$ coil in the No. $m$ coil work-base can be expressed as a function of the total weight of the upper coils and the convection plates.

$$
\sigma_{\max m i}=f\left(T_{m i}\right)
$$

where $\sigma_{\operatorname{maxmi}}$ is the maximum radial compressive stress of the No. $\mathrm{i}$ coil from top to bottom in the No. $\mathrm{m}$ coil workbase.

The sticking index of the serial number $n_{m i}$ coil can be obtained by Formulas (5) and (3), which can be expressed by Formula (6).

$$
\xi_{m i}=\frac{\sigma_{r \max m i}-\sigma_{r m i}^{*}}{\sigma_{r m i}^{*}}
$$

At the same time, a theoretical minimum coil work-base quantity exists for a batch of coils $N$ without considering any technology. This condition can be expressed by Formula (7).

$$
M^{*}=\frac{\sum_{m=1}^{M} \sum_{j=1}^{k_{m}} B_{m j}}{\eta H_{L u}}
$$

where $\eta$ is the furnace charging coefficient, generally $\eta=0.9$.

Therefore, the optimization of the furnace charging process in the bell-type annealing process involves optimizing the combination of a batch of coils under the condition of ensuring the coils are placed from large to small layer by layer in the same furnace to achieve two objectives: (1) charging with the coil work-base number $M$ as close as possible to the theoretical minimum $M^{*}$ to increase the annealing efficiency and (2) with the minimum average value of the sticking index and controlling the maximum value of the sticking index in a certain range in the same batch of coils, the corresponding objective function can be expressed by Formula (8).

$$
\left\{\begin{array}{l}
F(X)=\frac{\alpha}{N} \sqrt{\sum_{m=1}^{M} \sum_{j=1}^{k_{m}}\left(\xi_{m j}-\frac{1}{N} \sum_{m=1}^{M} \sum_{j=1}^{k_{m}} \xi_{m j}\right)^{2}}+\frac{(1-\alpha)}{N} \sum_{m=1}^{M} \sum_{j=1}^{k_{m}} \xi_{m j} \\
\xi_{m j}<0 \\
R_{m j} \leq R_{m(j+1)} \\
\max \left\{\left|h_{m i}-h_{m j}\right|\right\} \leq \Delta h \\
i=1,2, \cdots, k_{m} \\
j=1,2, \cdots, k_{m}
\end{array}\right.
$$

where $h_{m i}$ is the thickness of the No. $\mathrm{i}$ coil in the No. $\mathrm{m}$ coil work-base, $h_{m j}$ is the thickness of the No. $\mathrm{j}$ coil in the No. $\mathrm{m}$ coil work-base, $\Delta h$ is the maximum thickness specification difference that the process allows for any two coils in the mixed charging of different thickness specifications in the bell-type annealing process, generally $\Delta h \leq 0.35 \mathrm{~mm}, X$ is the sequence of coils, and $\alpha$ is the weighting coefficient.

Thus, the entire furnace charging optimization problem is converted into the following issue: the coil quantity for furnace charging is $N$, and the optimized result can be quickly obtained by finding the optimal combination to minimize the multi-objective function ${ }^{19-21)}$ under the condition of ensuring the coil work-base number $M$ is as close as possible to the theoretical minimum $M^{*}$.

Finally, given the differences of specific coil in the coiling technology, the coil size, the product specifications, and the annealing technology in the same batch program, the corresponding radial stress caused by coiling tension and thermal stress is different. Thus, the abovementioned factors have been considered in the sticking index $\xi_{m i}$ of the specific coil in Formula (6). That is, the furnace charging optimization model considers not only the influence of stacking mode, but also the coiling technology, the coil size, the product specifications, the annealing technology, the temperature deviation in batch annealing system and the chemical surface conditions in the coils. This condition is one of the vital characteristics of this model.

\section{Introduction of the Model Field Application}

Early in the bell-type annealing line production of a cold-rolled sheet plant, the coils are charging based on the contract sequence. The utilization factor is low, but the sticking defect ratio is high. A software was developed using the furnace charging optimization model described in this paper to improve the utilization factor of the coil work-bases, decrease the occurrence rate of sticking, and realize smart furnace charging. This software automatically arranges furnace charging based on the contract batches (as shown in Fig. 4). After the software was used in the field, the furnace charging efficiency and productivity increased and the sticking defect rate decreased. Based on the tracking statistics results over a period of one year, after using the software, the production increased by $5.5 \%$ and the occurrence rate of sticking decreased by $12.4 \%$ with an annual economic benefit of more than $¥ 5000000$.

In order to further validate the practical application effects of the furnace charging comprehensive optimization technology of the bell-type annealing process, typical product 


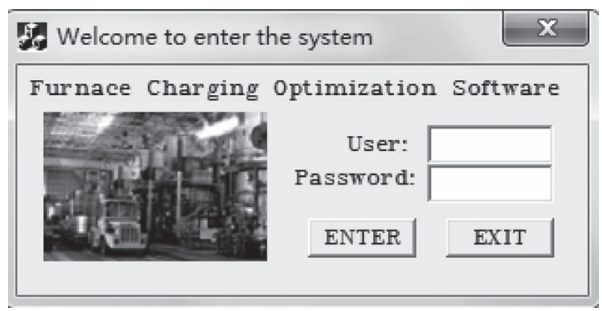

Fig. 4. Main interface of the furnace charging optimization software.

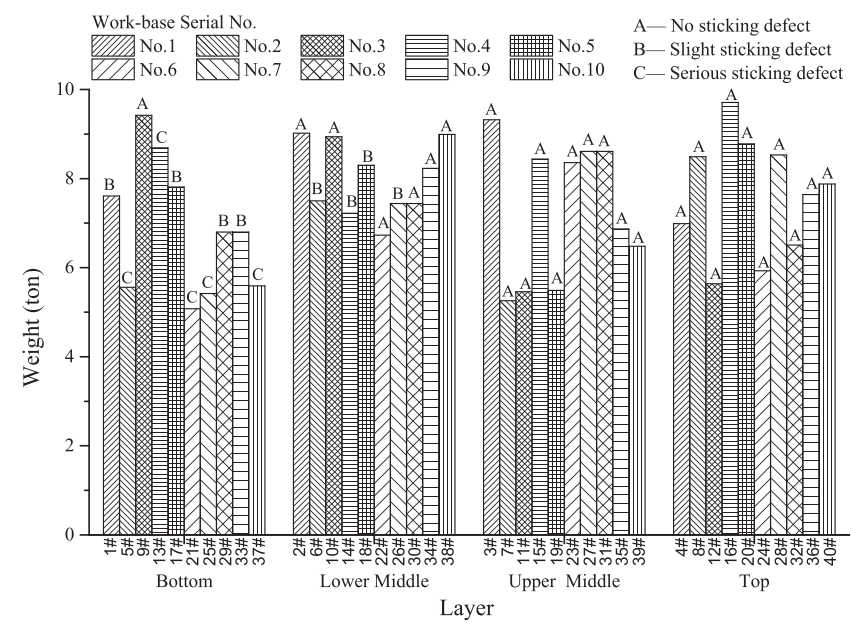

Fig. 5. The charging weight sequence and the corresponding sticking situation of the coils with the original charging method.

SPCC of a cold-rolled sheet plant was given as an example. 40 coils was selected, with each entry coil divided equally into two exit coils at the upstream degrease line. Thus, two identical groups of coils were obtained to comparing the sticking situation of the coils charging with original and optimal method in certain annealing schedule. The first group of coils was charged with the original method by the contract sequence and the second group of coils was charged with the optimal method by the charging comprehensive optimization technology. The parameters of the two identical groups of coils were shown in Table 1. The two identical groups of coils were annealed with the annealing temperature $620^{\circ} \mathrm{C}$ and the soaking time 10 hours.

The charging weight sequence and the corresponding sticking situation of the coils with the original charging method were shown in Fig. 5. The charging weight sequence and the corresponding sticking situation of the coils with the optimal charging method were shown in Fig. 6. The sticking index distribution and the corresponding sticking situation of the coils with the original charging method were shown in Fig. 7. The sticking index distribution and the corresponding sticking situation of the coils with the optimal charging method were shown in Fig. 8. The outlook of coil surface corresponding to the sticking situation A-C were shown in Fig. 9. Photos of the scene of the test and series of the coils were shown in Fig. 10.

Figure 5 shows that five coils get serious sticking defect (all in the bottom layer of work-base No. 2, No. 4, No. 6, No. 7, No. 10) and eight coils get slight sticking defect (four in the bottom layer of work-base No. 1, No. 5, No. 8, No. 9 and four in the lower middle layer of work-base No.
Table 1. The parameters of the two identical groups of coils.

\begin{tabular}{|c|c|c|c|c|c|c|}
\hline $\begin{array}{l}\text { Coil } \\
\text { No. }\end{array}$ & $\begin{array}{l}\text { Width } \\
(\mathrm{mm})\end{array}$ & $\begin{array}{l}\text { Thickness } \\
\text { (mm) }\end{array}$ & $\begin{array}{l}\text { Outer Dia. } \\
\quad(\mathrm{mm})\end{array}$ & $\begin{array}{l}\text { Inner Dia. } \\
\quad(\mathrm{mm})\end{array}$ & $\begin{array}{c}\text { Weight } \\
\text { (ton) }\end{array}$ & $\begin{array}{c}\text { Coiling } \\
\text { Tension } \\
\text { (MPa) }\end{array}$ \\
\hline $1 \#$ & 1020 & 0.20 & 1185 & 420 & 7.61 & 30 \\
\hline $2 \#$ & 1020 & 0.25 & 1277 & 420 & 9.02 & 30 \\
\hline $3 \#$ & 1010 & 0.25 & 1296 & 420 & 9.32 & 30 \\
\hline $4 \#$ & 1010 & 0.20 & 1142 & 420 & 6.99 & 30 \\
\hline $5 \#$ & 1005 & 0.25 & 1036 & 420 & 5.56 & 30 \\
\hline $6 \#$ & 1005 & 0.25 & 1177 & 420 & 7.50 & 30 \\
\hline $7 \#$ & 995 & 0.25 & 1012 & 420 & 5.26 & 30 \\
\hline $8 \#$ & 993 & 0.22 & 1243 & 420 & 8.49 & 30 \\
\hline 9\# & 991 & 0.25 & 1302 & 420 & 9.42 & 30 \\
\hline $10 \#$ & 987 & 0.20 & 1272 & 420 & 8.94 & 30 \\
\hline $11 \#$ & 987 & 0.22 & 1028 & 420 & 5.46 & 30 \\
\hline $12 \#$ & 986 & 0.18 & 1042 & 420 & 5.64 & 30 \\
\hline $13 \#$ & 982 & 0.22 & 1256 & 420 & 8.69 & 30 \\
\hline $14 \#$ & 971 & 0.25 & 1158 & 420 & 7.22 & 30 \\
\hline $15 \#$ & 960 & 0.25 & 1240 & 420 & 8.44 & 30 \\
\hline $16 \#$ & 958 & 0.20 & 1320 & 420 & 9.71 & 30 \\
\hline $17 \#$ & 956 & 0.22 & 1198 & 420 & 7.81 & 30 \\
\hline $18 \#$ & 954 & 0.18 & 1231 & 420 & 8.30 & 30 \\
\hline $19 \#$ & 953 & 0.18 & 1030 & 420 & 5.49 & 30 \\
\hline $20 \#$ & 953 & 0.22 & 1262 & 420 & 8.78 & 30 \\
\hline $21 \#$ & 951 & 0.22 & 998 & 420 & 5.08 & 30 \\
\hline $22 \#$ & 950 & 0.22 & 1123 & 420 & 6.73 & 30 \\
\hline $23 \#$ & 943 & 0.25 & 1235 & 420 & 8.36 & 30 \\
\hline $24 \#$ & 933 & 0.25 & 1064 & 420 & 5.93 & 30 \\
\hline $25 \#$ & 925 & 0.25 & 1025 & 420 & 5.42 & 30 \\
\hline $26 \#$ & 924 & 0.25 & 1173 & 420 & 7.44 & 30 \\
\hline $27 \#$ & 919 & 0.20 & 1251 & 420 & 8.61 & 30 \\
\hline $28 \#$ & 917 & 0.18 & 1246 & 420 & 8.53 & 30 \\
\hline $29 \#$ & 917 & 0.20 & 1128 & 420 & 6.80 & 30 \\
\hline $30 \#$ & 916 & 0.18 & 1173 & 420 & 7.44 & 30 \\
\hline $31 \#$ & 910 & 0.20 & 1251 & 420 & 8.61 & 30 \\
\hline $32 \#$ & 899 & 0.18 & 1107 & 420 & 6.51 & 30 \\
\hline $33 \#$ & 892 & 0.18 & 1128 & 420 & 6.80 & 30 \\
\hline $34 \#$ & 887 & 0.20 & 1226 & 420 & 8.23 & 30 \\
\hline $35 \#$ & 859 & 0.25 & 1133 & 420 & 6.87 & 30 \\
\hline $36 \#$ & 857 & 0.20 & 1187 & 420 & 7.64 & 30 \\
\hline $37 \#$ & 840 & 0.25 & 1038 & 420 & 5.59 & 30 \\
\hline $38 \#$ & 827 & 0.18 & 1275 & 420 & 8.99 & 30 \\
\hline $39 \#$ & 827 & 0.18 & 1105 & 420 & 6.48 & 30 \\
\hline $40 \#$ & 826 & 0.20 & 1203 & 420 & 7.88 & 30 \\
\hline
\end{tabular}

2, No. 4, No. 5, No. 7) with the original charging method. Figure 6 shows that no coil get serious sticking defect and only three coils get slight sticking defect (all in the bottom layer of work-base No. 3, No. 6, No. 8) with the optimal charging method. Figures 7 and 8 shows that the average 
sticking index of the coils decline from -0.10 to -0.35 and the maximum sticking index decline from 0.55 to -0.01 by charging technology optimization. Figures 7 and 8 also shows that sticking defects scarcely occurs when sticking

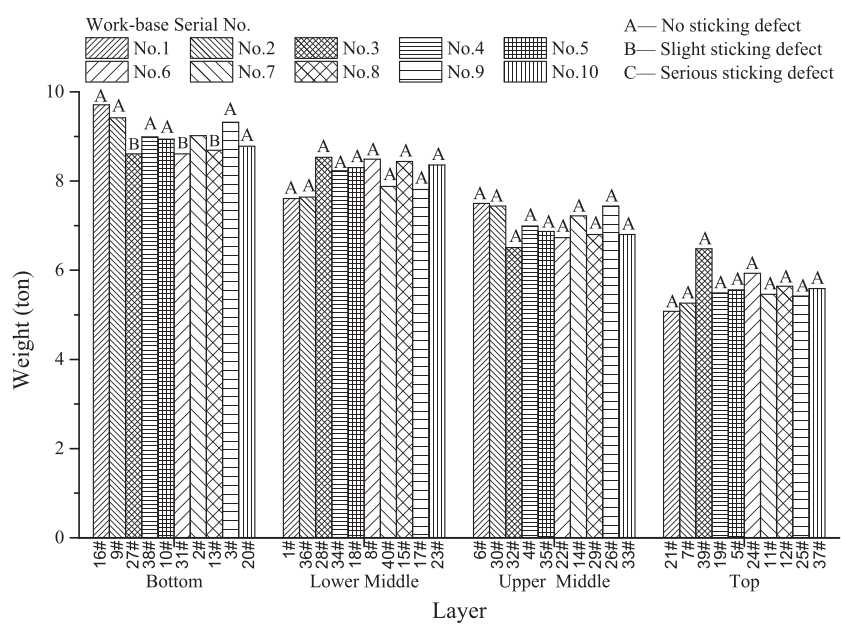

Fig. 6. The charging weight sequence and the corresponding sticking situation of the coils with the optimal charging method.

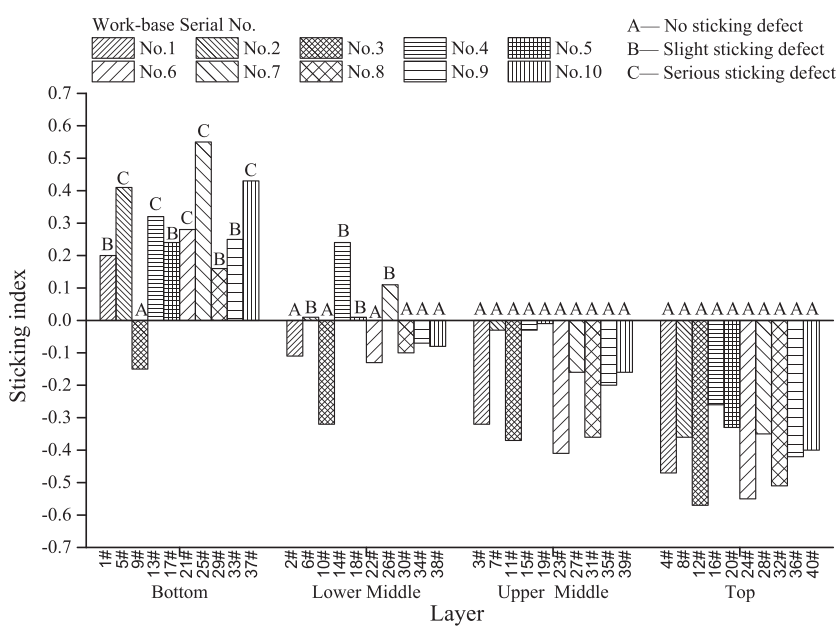

Fig. 7. The sticking index distribution and the corresponding sticking situation of the coils with the original charging method.

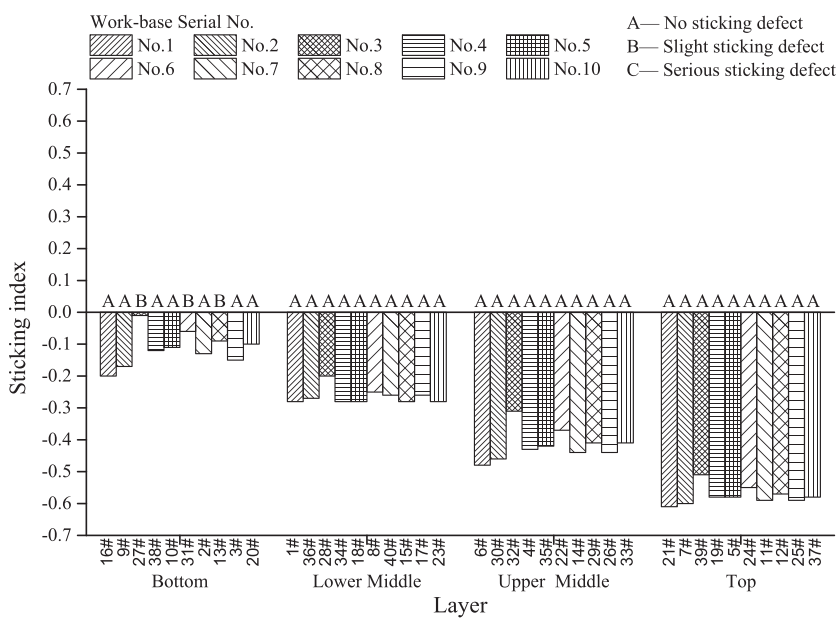

Fig. 8. The sticking index distribution and the corresponding sticking situation of the coils with the optimal charging method. index less than -0.10 , slight defects may occurs when sticking index between -0.10 to 0 and probably occurs when sticking index between 0 to 0.26 , serious defects possibly occurs when sticking index between 0.26 to 0.28 and probably occurs when sticking index more than 0.28 . The result of Figs. 5 and 6 conforms to the calculated sticking index in Figs. 7 and 8. This indicates that the furnace charging comprehensive optimization technology is effective to decline the sticking defect of the bell-type annealing line.

\section{Conclusion}

Previous studies considered only efficiency and ignored defect prevention in the bell-type annealing process. Thus, this study considered the equipment and technological characteristics of the bell-type annealing line to analyze

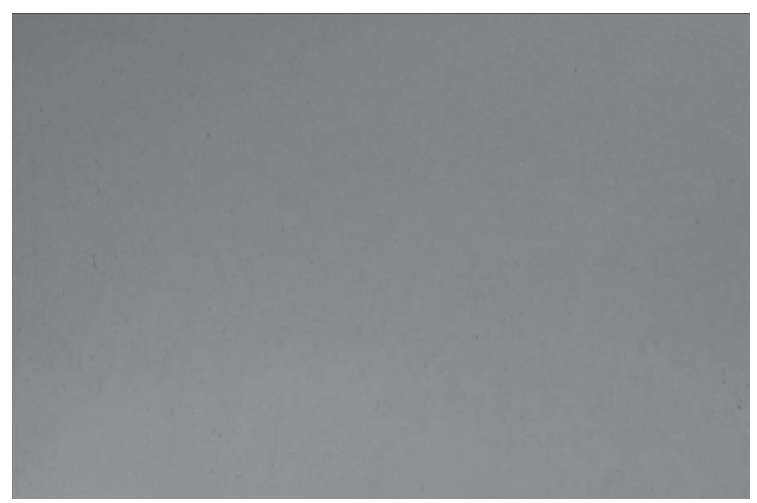

(a) Sticking situation A(no sticking defect)

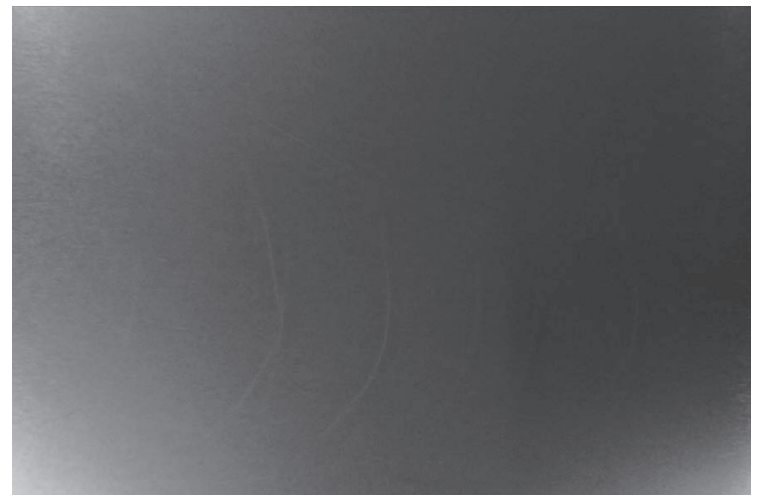

(b) Sticking situation B(slight sticking defect)

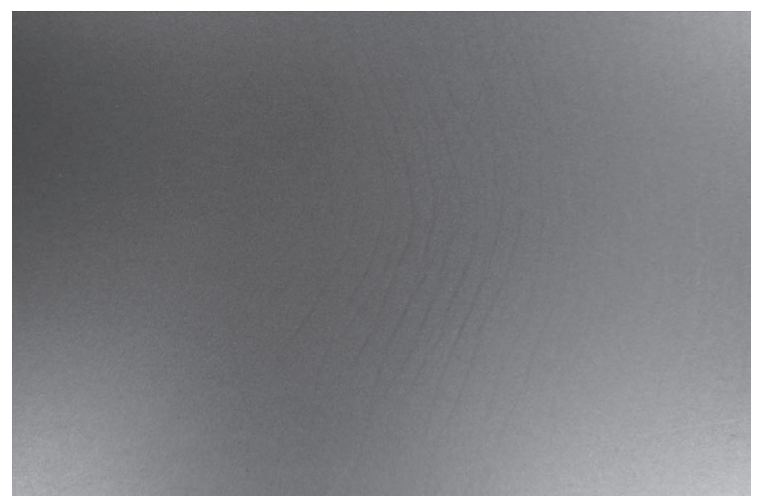

(c) Sticking situation $\mathrm{C}$ (serious sticking defect)

Fig. 9. The outlook of coil surface corresponding to the sticking situation $\mathrm{A}-\mathrm{C}$. 

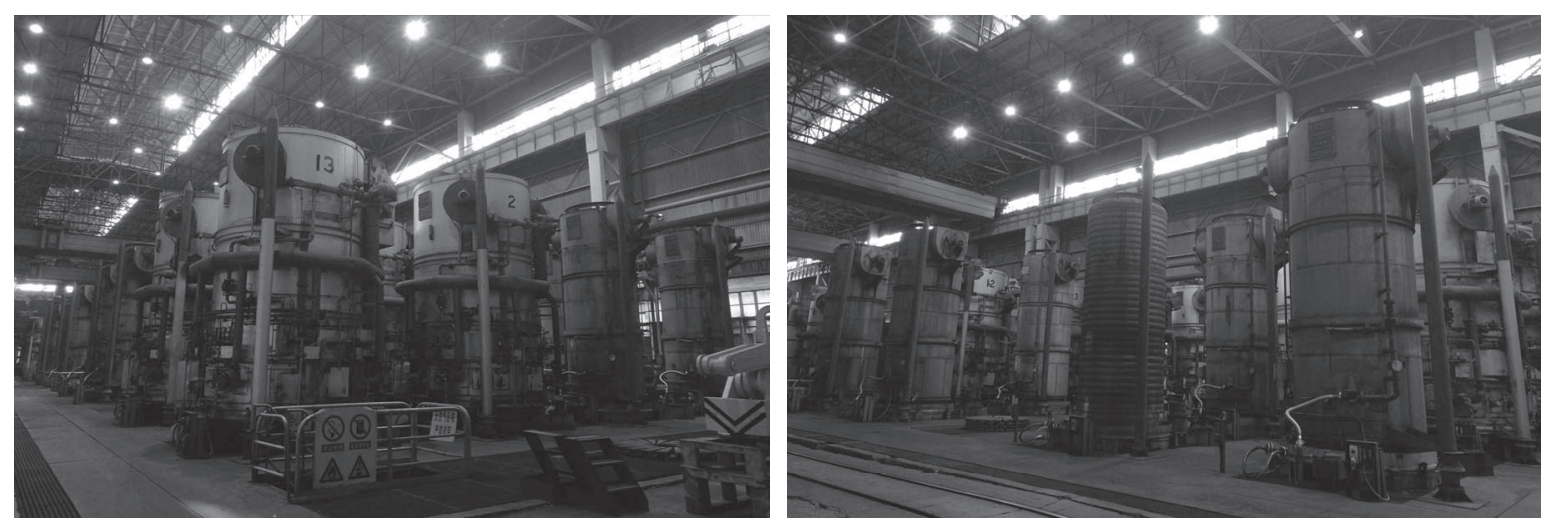

(a) Scene of the test
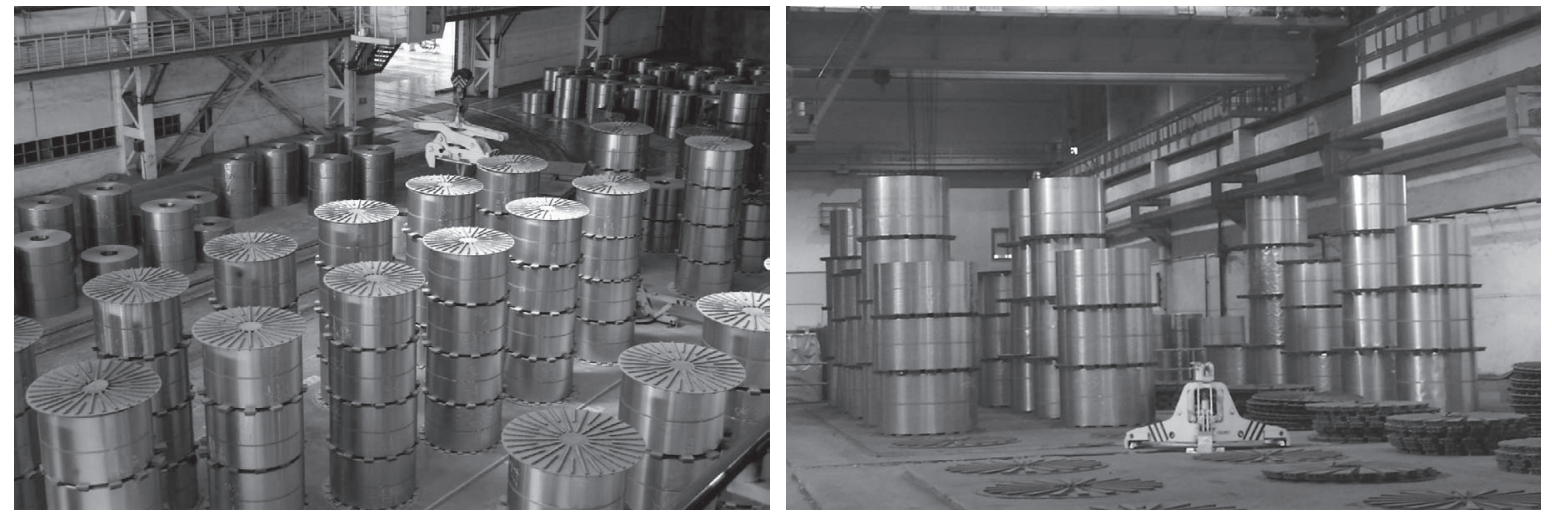

(b) Series of the coils

Fig. 10. Photos of the scene of the test and series of the coils.

the influence mechanism of the furnace charging process on sticking defect and defined the concept of sticking index. The internal stress of the coil influenced by the coiling process, the coil size, the product specifications, and the annealing process were fully considered in this study. Multiple objective function optimization was adopted, production efficiency and defect prevention were balanced. The coil work-base quantity was ensured to be as close as possible to the theoretical minimum, the average and the peak of the sticking index of the same batch of coils after charging as the target were minimized. A suitable furnace charging comprehensive optimization technology of the bell-type annealing process that aimed to prevent sticking was introduced, and it was applied to the production practice of a cold-rolled sheet plant. This method was effective to decline the sticking defect of the bell-type annealing line, which achieved good using effect, increased production by $5.5 \%$, decreased the occurrence rate of sticking by $12.4 \%$, and created a significant economic benefit for the enterprise, with further popularization and application values.

\section{Acknowledgements}

This work is supported by the Natural Science Foundation of Hebei Province (Grant No. E20160203385) and the Heavy machinery Collaborative Innovation Program (Grant No. ZX01-20140400-05). A few experiments were made in Baosteel cold-rolled sheet Plant. The authors gratefully acknowledge the technical support of Baosteel.

\section{REFERENCES}

1) P. R. Wilson, Z. Chen, C. R. Killmore, S. J. Laird and J. G. Williams: ISIJ Int., 47 (2007), 114.

2) S. Tajima, K. Komine, T. Shibashita and M. Shirouzu: Tetsu-to-Hagané, 77 (1991), 1288

3) O. Pawelski, W. Rasp and G. Martin: Stahl Eisen, 109 (1989), 178.

4) X.-c. Zhang and S.-f. Jiang: Ind. Heat., 36 (2007), 56.

5) S. S. Sahay, A. M. Kumar and A. Chatterjee: Ironmaking Steelmaking, 31 (2004), 144.

6) B. Jiang, Z.-y. Jiang and X.-x. Zhang: Energy for Metallurgical Industry, 24 (2005), 19, (in Chinese).

7) S. J. Park, B. H. Hong, S. C. Baik and K. H. Oh: ISIJ Int., 38 (1998), 1262.

8) K. Tanaka: Tetsu-to-Hagané, 44 (1958), 1165.

9) H. Nakashima, A. Ikeda and H. Tanabe: Tetsu-to-Hagané, 80 (1994), 78.

10) J. T. Park, J. A. Szpunar and S. Y. Cha: ISIJ Int., 43 (2003), 1611.

11) Y. Liu, Q.-1. Liu and W. Wang: Inf. Control, 38 (2009), 211.

12) J. Li: China Metallurgy, 16 (2006), 18, (in Chinese).

13) X.-p. Zhang, W. Wang, Q.-1. Liu and J. Zhao: J. Syst. Simul., 21 (2009), 3894.

14) X.-d. Wang, Q.-1. Liu, W. Wang and H. Shi: J. Shandong Univ. (Eng. Sci.), 35 (2005), 20.

15) Q.-l. Liu, W. Wang, R.-j. Zhu, N. Li and J.-1. Jin: Acta Autom. Sin., 30 (2004), 974.

16) T.-z. Chang, Q.-d. Zhang and J. Ding: Iron Steel, 43 (2008), 56.

17) J.-q. Sun and J.-c. Lian: J. Yanshan Univ., 22 (1998), 222.

18) Y.-q. Ma and Y. Liu: Metal Materials and Metallurgy Engineering, 37 (2009), 39, (in Chinese).

19) Z.-g. Wang, Q.-1. Liu and W. Wang: Control Eng., 17 (2010), 197.

20) M. Mahfouf, M. Chen and D. A. Linkens: ISIJ Int., 45 (2005), 694.

21) S. Datta, F. Pettersson, S. Ganguly, H. Saxen and N. Chakraborti: ISIJ Int., 47 (2007), 1195. 